\title{
Breccia Negro: el testimonio de un autor
}

\section{Turnes, Pablo}

Resumen:

En 1978 se publicó el volumen Breccia Negro, que significó la presentación ante un público argentino de un Alberto Breccia consagrado como autor, premiado en Europa pero relativamente desconocido en Argentina. De esta manera, se trataría de una re-presentación en su doble sentido: la renovación de la presencia del dibujante, de larga trayectoria en el país; y de la representación de su persona artística y autoral, en un momento donde la posibilidad de pensar en una figura tal no sólo era posible sino que además era requerido por un público progresivamente más refinado, especializado, crítico y exigente. Por otra parte, el mismo autor elegía reconstruir su pasado como trabajador

Cuadernos del Centro de Estudios de Diseño y Comunicación №74

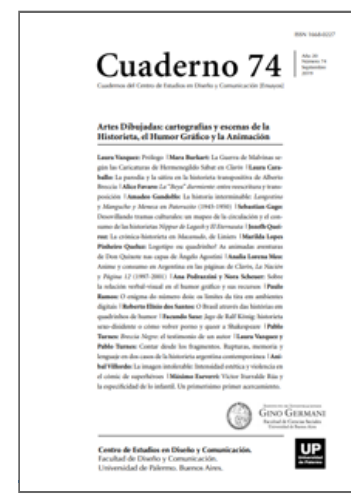

ISSN: 1668-0227

Artes Dibujadas:

cartografías y

escenas de la

Historieta, el Humor

Gráfico y la

Animación

Año XX, Septiembre 2019, Buenos

Aires, Argentina | 256 páginas

descargar PDF

ver índice de la publicación

Ver todos los libros de la publicación

compartir en Facebook

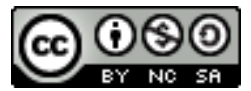

Esta obra está bajo una Licencia Creative Commons Atribución-NoComercialCompartirlgual 4.0 Internacional de una industria desde esa perspectiva personal y autoral, haciendo recortes y filtrando aquello que podía contribuir a la operación separándolo de aquello otro que no tenía lugar en ese corpus. Breccia Negro, además, puede leerse como la unión de dos factores que hasta ese momento, si bien de alguna manera siempre estaban presentes, comenzaban ahora a transformarse en acción deliberada: la experimentación gráfico-narrativa y el contenido político de las historietas.

Palabras clave: Alberto Breccia - Dictadura - Autoría - Historieta.

$\left({ }^{*}\right)$ Profesor en Historia por la Universidad Nacional de Mar del Plata; Magíster en Historia del Arte Argentino y Latinoamericano por el Instituto de Altos Estudios Sociales/Universidad Nacional de San Martín; Doctor en Ciencias Sociales por la Universidad de Buenos Aires/CONICET. Jefe de Trabajos Prácticos en la cátedra Historia de los Medios de Comunicación Argentina y Latinoamericana, dirigida por Laura Vazquez, para la Licenciatura en Comunicación Social, Universidad Nacional de Moreno. "Es blanco y negro. Pero para llegar a eso hice todo ese recorrido. Me llevó más tiempo pensarlo y resolverlo que dibujarlo". Alberto Breccia (Sasturain, 2013, p. 251) 
La aparición en 1978 del volumen titulado secamente como Breccia Negro cobra una importancia clave. Editado por Record, el volumen proponía un recorrido por la obra de Breccia, seleccionada por él mismo bajo esa lógica del descarte implacable que solía ejercer sobre su trabajo, aunque no habría que subestimar la limitación editorial2 . En su prólogo, Saccomanno volvía explícita la operación llevada a cabo por el volumen:

La impresión que queda tras leer este libro es la de hallar por primera vez, en muchos años, autores y piezas, a un artista que sabe devolver al género su perdida aura plástica. Por fin, me digo, un artista capaz de arrojar una nueva mirada sobre ese bruñido objeto que es la realidad. Por fin, la historieta cuenta nuevamente con un creador que a través de su prisma evidencia crédito en los hombres y en el porvenir, aunque para decirlo emplee una sombría acidez, cruel y devastadora en apariencia. (Breccia, 1978, p. 6)

Así, se llegaba al momento de consagración autoral y a una bisagra que, al mismo tiempo, era restauradora de la "perdida aura plástica" de la historieta. Si bien Saccomanno no aclaraba en qué momento se había perdido dicha aura, y qué historietas eran esas que la poseían, podemos interpretarlo -teniendo en cuenta la admiración de Breccia por aquellos historietistas norteamericanos de principios del siglo XX-como un movimiento que reconstruía líneas hasta entonces inexistentes entre aquellos maestros del pasado y al menos uno, Breccia, del presente.

Sin embargo, bastaba con observar esa particular evolución del tratamiento gráfico de las historietas para darse cuenta cuánto, en esa indagación constante, ansiosa y a menudo violenta y oscura del lenguaje, se había alejado de aquellas primeras páginas ahora consideradas verdaderos clásicos.

No hay que perder de vista que esta operación autoral sólo podía ser concretada en un formato que diera cuenta desde la materialidad misma que la contenía, que algo había cambiado de manera profunda y definitiva: se trataba de un libro de tapa dura, de riguroso blanco y negro, con una portada de Enrique Breccia al estilo xilográfico retratando a su padre (Ver Figura 1). No se trataba de una revista de tal o cual historieta o personaje, sino de un libro perteneciente a un autor3 .

Ya habíamos mencionado cómo de pronto Breccia se había visto trasladado al campo autoral, mientras lamentaba que ese movimiento implicara su alejamiento de lo popular -un campo que ya no existía en los términos en que se anhelaba-. Y he ahí la paradoja: ahora que se habían logrado abrir nuevas posibilidades exploratorias para las fronteras del lenguaje historietístico, la fragmentación de los públicos y del consumo habían llevado a que la demanda de ese tipo de trabajos fuera minoritaria y para un tipo de lector acaso más especializado y refinado.

Esto no quería decir que hubiera dejado de existir un público masivo en la escala similar a la de antaño, pero frente a un mercado golpeado por las medidas económicas y censoras de la dictadura, la producción era pobre e ideológicamente hostil hacia tipos de experimentación que enrarecieran con demasía la transparencia del relato -sin que por esto, desde ya, hayan dejado de producirse buenas obras-.

También aquí se jugaba una dimensión político-ideológica, de la cual algunas de las historias de ese volumen daban cuenta, si propendemos a una lectura en conjunto y teniendo en cuenta el contexto argentino de 1978. De las cinco historias unitarias, cuatro estaban basadas en cuentos literarios y de autores del tipo que gustaban a 
Breccia, es decir, desde el horror, lo oculto, el terror, etc. Hablamos de Edgar Allan Poe, Horacio Quiroga, William W. Jacobs y Lord Dunsany.

El autor de la historieta restante, "Miedo", era ni más ni menos que Oesterheld, quien había trabajado para Columba al momento de realizarla, algo a lo que Breccia siempre se negó -y es interesante tener esto en cuenta, ya que pretendía alcanzar masivamente al público sin renunciar a la calidad del trabajo, posibilidad obturada por aquello en lo que su obra y aquel público se distanciaban en intereses estéticos e ideológicos-.

En términos generales, el tratamiento gráfico es una gran mixtura de los diferentes registros que Breccia venía trabajando desde El Eternauta y donde se encuentran recursos compartidos desde la simultaneidad de trabajos como Los Mitos de Cthulhu y Un tal Daneri. Está claro que se trata de una vieja obsesión brecciana: cómo narrar lo inenarrable, cómo dibujar aquello que no es otra cosa que una sensación, un paisaje mental que distorsiona la realidad (Ver Figura 2).

La organización del volumen hace que a "Miedo" siga "El corazón delator", y es sin dudas un acierto de Breccia, quien explicaba que en principio el editor Scutti se había negado a incluir la historia en el volumen, lo cual daba una pauta de aquellos límites que tal experimentación encontraba en el ámbito local: "Si yo hago para acá El corazón delator, no me lo publican. Se publicó en el Breccia Negro que sacó [Alfredo] Scutti, porque yo lo impuse" (Sasturain, 2013, p. 264). La versión del relato de Poe adquiere otro tenor si se tiene en cuenta como un trabajo inserto en una línea genealógica de la cual "Miedo" había sido una primera aproximación, reduciendo la idea básicamente a tres elementos: síntesis, iteración, ritmo.

La historieta en sí misma deviene cadencia de lectura: se trata de pocas viñetas, en blanco y negro, sin fondos, que son repetidas, ampliadas o reducidas creando el efecto de una secuenciación cinematográfica pero que en realidad remiten a la capacidad de la imagen de adquirir un sentido propio, que el lector reconstruye para sí especialmente cuando no hay texto-. Toda la historieta puede ser descompuesta en una serie limitada de viñetas que se alternan repitiéndose.

La grilla de nueve paneles, el blanco recortado sobre el negro y la ausencia de escenarios y detalles ambientales logra un despojo tal que deriva en la exposición radicalizada de la cadencia sobre la que se mueve el relato, explicitación de la potencia de cada viñeta en sí misma a través de la exacerbación de ese esquematismo.

La repetición de los paneles -que apenas se ven modificados por algún movimiento o por el uso del zoom- sirve para identificarlos en su singularidad inscripta en la grilla predeterminada e inmutable. El crimen es perpetrado dentro de ese férreo mundo de la cuadratura reproducida hacia afuera, por los márgenes, y hacia adentro por la puesta en página. Breccia se limitó a cumplir con la homogeneidad del estilo, pero lo utilizó para acelerar y desacelerar el ritmo del relato, de manera que no fuera necesario completar una imagen faltante sino someterse a esa cadencia rigurosa que nos sitúa frente a viñetas similares y distintas cada vez 4.

El salto de viñeta a viñeta construye su lectura con la ralentización y la aceleración como lógica operativa similar al staccato musical-. Breccia no pretende (re)contar el cuento de Poe, sino que excusándose en una adaptación literaria expuso una forma de contar y de leer, completamente diferente y específica: la historieta. A esto último debe sumársele el contexto histórico y el momento de crisis institucional argentina irrumpe en ese 
mundo en los tres personajes -la policía de civil, símil de la Triple A-. Los personajes trasladan desde y hacia el interior del relato la tensión entre singularidad y repetición: una reproductibilidad singularizada 5.

Las viñetas finales, con ese TUMP que hace presente el crimen enterrado en el subsuelo de la conciencia del asesino; y la imagen final de la confesión hacen de El Corazón Delator de Breccia un punto de conexión con devenir histórico de los mecanismos represivos del Estado, y por lo tanto con las formas de presentar esos mecanismos: un lenguaje y un medio que se evidencian a sí mismos y que -al menos por esta vez- no intentan disimularlo (Ver Figura 3) 6.

Todo lo contrario: el recorte de ese universo condensado, repetitivo, casi xilográfico, nos asalta con sus staccatos que componen la cadencia. Esa transposición funciona como construcción/revelación de aquello que se encontraba en la fuente del relato pero que cobra sentido en un momento determinado, en ese movimiento que implica también tejer esas líneas invisibilizadas, ahora explícitas:

Al dar lugar en sus desarrollos a la complejidad y la tensión, la transposición invierte el sentido habitual de sus producciones; y lo hace, en unos casos, recuperando sentidos perdidos u ocultos -en versiones anteriores- de la obra o el género transpuestos, y en otros introduciendo cambios que son fracturas ideológicas, en el sentido de que introducen nuevas claves generales de lectura. Pero en cualquiera de ambas opciones la transposición abandona previsibilidades pasando, si se parafrasea la formulación de un creador contemporáneo de la narrativa mediática, "de la palabra c a la palabra h"; es decir, de la continuidad a la historia. (Steimberg, 2013b, pp. 208209)

La consolidación narrativa de la historieta, la ubica en ese espacio otro construido por su propio traslado desde lo literario; deviene original en sus propios términos. Así como los parámetros de construcción del relato mutan inevitablemente para posibilitar su traslado, también deben cambiar los términos de su recepción. Es decir que implican un programa de lectura diferente (Steimberg, 2013b, p. 213).

Un cuento que hoy podríamos considerar como thriller policial, o género negro, puede ser así definido en perspectiva a partir de su cambio transposicional: de alguna manera, la adaptación perturba el original, la excepción cambia la regla, la operatoria sobre un corpus instalado previamente deja huellas mnemónicas al (re)establecerse como género. Y esa memoria afectada no es meramente cultural, sino que en sentido inverso, lo cultural es la memoria, y ambos se definen en acto, en su producción, reproducción, recepción y ambivalencia7 .

Hay dos claves en principio: el cine y el teatro. De un lado, los mitos griegos, y el teatro como su vehículo material; por otro, el cine como medio definitivo de la sociedad industrial de masas y su cultura. Pero Breccia agrega la historieta desde el desafío narrativo, en un cómo contar resolviendo gráficamente aquello que provenía de un cuento gótico decimonónico pero cuya trama bien puede ubicarse en aquellos orígenes griegos: los del crimen, la culpa y el castigo en forma de aparición inesperada, enviada por una autoridad superior e implacable.

Dicha resolución se vuelve, en manos del dibujante, en un proceso de ascesis, donde debe despojarse de todo incluyendo sus vicios aprehendidos en casi 40 años de oficio- y donde para desafiar a sus lectores a 
desaprender las formas de lecturas adquiridas, debe comenzar por desaprender él mismo desde la reconstrucción fundamental, desde los basamentos narrativos.

El factor a tener en cuenta, lógica matriz de la historieta, es el de la redundancia -o sobre-redundancia, como lo llama Steimberg (2013a, p. 149)-, aquí explicitado por esa ralentización del recurso cinematográfico -lo cual constituye finalmente su negación- y la revelación de lo que es: la puesta en página, con la elección de las imágenes, de su encadenamiento y su sutura, su ritmo y cadencia, como una elección política e ideológica tanto por parte del autor como del lector. Y no por una cuestión de contenido, sino en la misma experiencia de construcción narrativa, en el otorgamiento de sentido a esos paneles que se despliegan por la página, sin salir nunca de ella. Thierry Groensteen lo ha definido como el arte de la economización de la redundancia (2007, p. 117).

La historia gemela a "El corazón delator" fue "La gallina degollada", basada en el relato de Horacio Quiroga, en colaboración con Trillo. Si bien esta última fue realizada en 1975, fue recién publicada en 1978 en Breccia Negro. El procedimiento formal fue, una vez más, motivo de conflictos editoriales ya que el dibujante había elegido un recurso que era clave para la "resolución gráfica" de la historia: el blanco y negro debía quebrarse con solo un color, el rojo8 .

Lo único que alcanzan a decir los hijos idiotas, víctimas de sucesivas meningitis infantiles, es "rojo". En el cuento hay apenas una sola línea reservada para ese parlamento, donde se multiplica la invocación del color: "rojo... rojo...rojo....". En la versión de Breccia/Trillo, la línea es repetida en consonancia con las diferentes apariciones del color rojo: el de la sangre y el que habita en las pupilas de los idiotas como deseo absoluto.

De esta manera, la veta iterativa comprobaba con Poe, se potencia con la multiplicación de la idiotez de los personajes como existencia repetitiva, una rutina patética que solo encuentra su quiebre con la aparición del color (Ver Figura 4). Steimberg también reflexionaba en torno a esta cualidad de la historieta de Breccia:

La versión de "La gallina degollada" va más allá: el rojo que obsesiona a los idiotas del cuento -y que los hará fascinarse ante el color de la sangre de la gallina sacrificada, y luego ante el rojo de la que ellos mismos vierten en su crimen- recorre las sucesivas secuencias como una segunda melodía (único elemento de color en la producción en blanco y negro) que profundiza el continuo de la obsesión y de su verdad psicológica, y ahora estética: esa verdad que alienta muchas veces en forma oculta en los cuentos de Quiroga, reprimida por sus ideas explícitas, y que aquí estalla convocada por el dibujo de un historietista irrespetuoso [...] (2013a, p. 153).

Así, queda para los monstruos el inicio y el cierre del melodrama, y los lectores se ven confrontados con el horror que deben reconstruir desde ese rojo que adquiere un significado preciso en ese contexto -los colores en sí mismos no tienen sentido alguno, sino que son culturalmente traducidos para obtenerlo-; significado que sugiere brutalmente pero que no termina de cerrarse, como una herida que sangra, que no puede dejar de hacerlo incluso después que ha concluido la lectura, como quien cierra los ojos pero sigue viendo destellos detrás de los párpados.

"El corazón delator" y "La gallina degollada" conjugaban desde dos perspectivas literarias inscriptas en el género gótico -el anglo-norteamericano y el sudamericano- las posibilidades de experimentación desde el lenguaje historietístico hacia las formas del relato nacidas -como la historieta- dentro de la cultura de masas, en su 
necesidad de inventar nuevas maneras de llegar a un público y de sostener un oficio en base a esas posibilidad de relato impactante y regular.

Debe entenderse que en ese despliegue de técnica repetitiva que hace a la historieta en sí cada vez, y al mismo tiempo la constituye como una continuidad lingüística y semántica específica, pueden encontrarse una manera de asentar posiciones singulares desde dentro de la maquinaria de la cultura de masas, desde un aquí y ahora que transcriba las angustias del presente dejando huellas mnemónicas en esa gran red tejida por las memorias colectivas, y donde obras como estas pueden servir de nodos dentro de esa red que contengan, resguarden, y condensen significados lo suficientemente importantes y radicales como para proponerse vía alternativa a la otra redundancia infinita, la de la mercancía.

\section{Notas $<$}

1. Ponencia presentada en Congreso Latinoamericano de Comunicación - Preguntas, abordajes y desafíos contemporáneos del campo comunicacional 30 años de recorridos en Buenos Aires, Carrera de Ciencias de la Comunicación. Facultad de Ciencia Sociales, Universidad de Buenos Aires, 18 al 21 de agosto de 2015.

2. El volumen recogía cronológicamente las siguientes historietas: "El tranvía", de Sherlock Time; "La torre de Babel”, de Mort Cinder; Richard Long; “El duelo", "El Bagre”, "Ojo por ojo” y “Ojos dorados”, de Un tal Daneri; y las historias unitarias "Miedo", "El corazón delator", "La gallina degollada”, "La pata de mono" y "Donde bajan y suben las mareas". Una segunda versión llamada Breccia Negro versión 2.0 fue publicada por Doedytores en 2006, recopilando una nueva serie de historias, la mayor parte producidas después de 1978.

3. Si seguimos a Scolari, podemos entender también la excepcionalidad brecciana con respecto a la norma impuesta en esa misma década: "La consolidación a partir de los años '70 de los mecanismos comerciales entre las editoriales Record y Columba y sus pares europeas [...] ejercieron una fuerte influencia sobre la historieta argentina. Las consecuencias de esta dependencia fueron evidentes: la sobreproducción industrial de historietas, el achatamiento del nivel creativo y la construcción, en el mejor de los casos, de un cómic oesterheldiano más o menos fiel a la escuela del gran maestro. Lo que en los años ‘ 50 había representado una revolución narrativa, a partir de los '70 se convirtió en regla. [...] Estos desniveles aparecen especialmente en las obras de historietistas que trabajan para diversos circuitos (popular o de autor) que [...] no siempre coinciden de país en país". (1999, p. 269)

4. El término homogeneidad del estilo pertenece a Groensteen, a quien cito: "Esta diversidad de la escritura gráfica se encuentra dentro de las historietas, pero a ella se agrega una propiedad por la que la historia en imágenes se opone una vez más a la historia literaria: el grado de precisión de la imagen permanece más o menos igual, sea cual fuere el motivo representado (sitio, objeto, personaje). Si la imagen es descriptiva, lo es igualmente para todos los motivos convocadas por la historia, otorgándoles a cada uno el mismo cuidado [...] la regla que prevalece es la de la homogeneidad de estilo de la imagen. La historia en imágenes es, por lo tanto, mucho menos discriminadora que el texto literario" (Groensteen, 2007, p. 123).

5. Andrei Molotiu propone un concepto interesante que sirve para pensar el ejemplo de El corazón delator, la iconoestasis: “[...] la percepción del diseño de una página de historieta como una composición unificada; percepción que no nos mueve tanto para rastrear la historieta de panel a panel en la dirección aceptada de la 
lectura, sino para incorporarlo de un solo vistazo, de la misma forma en que incorporamos una pintura abstracta". (2012, p. 91)

6. [...] una de las mejores cosas mías es El corazón delator, por cómo lo conté. Sigue siendo El corazón delator de Poe, pero yo lo conté de una manera muy especial, que a mí me gusta. No sé si es buena o mala [...] si lo mirás, es una tragedia griega. Entonces me acuerdo de las tragedias griegas, que son telón negro, las túnicas y poco más [...] Entonces decido eliminar todo lo que no sea personaje. O sea: la víctima, el victimario y la policía, que son tres tipos iguales, a los que les saco hasta los ojos. La Ley es una cosa casi sin cara. La Ley no tiene cara. (Sasturain, 2013, p. 250)

7. "[...] los géneros forman la memoria abierta de un número indefinido e ilimitado de artefactos que dialogan entre sí y que se conectan a través de pasajes intertextuales. Más que recordar enunciados concretos de la historia cultural, rescatan los modos de enunciación que forman la propia tradición cultural [...] la memoria constituye la condición misma de la comunicación. Como tal, surge de las estructuras conectivas que son formadas por los géneros" (Michael y Schäffauer, 2003, p. 5).

8. Existen algunas versiones que han sido publicadas íntegramente en blanco y negro, anulando todo el sentido del planteo de Breccia, lo cual habla de los límites y dificultades que encuentran las aproximaciones más experimentales en éste medio.

\section{Bibliografía<}

Breccia, A. (1978). Breccia Negro. Buenos Aires: Editorial Record.

Breccia, A. (2011). Edgard A. Poe. El Gato Negro y otras historias. Buenos Aires: Doedytores.

Groensteen, T. (2007). The system of comics. Mississippi: University Press of Mississippi. Traducción de Bart Beaty y Nick Nguyen.

Michael, J. y Schäffauer, M. K. (2003). “Géneros entre medios y memoria. Pasajes cronotópicos”, Figuraciones, No 1-2. Buenos Aires: Instituto Universitario Nacional del Arte.

Piglia, R. et. al. (1993). La Argentina en pedazos. Buenos Aires: Ediciones de la Urraca.

Scolari, C. A. (1999). Historietas para sobrevivientes. Comic y cultura de masas en los años 80. Buenos Aires: Colihue.

Sasturain, J. (2013). Breccia el Viejo: conversaciones con Juan Sasturain. Buenos Aires: Colihue.

Steimberg, O. (2013a). Leyendo historietas. Textos sobre relatos visuales y humor gráfico. Buenos Aires: Eterna Cadencia Editora.

Steimberg, O. (2013b). Semióticas. Las semióticas de los géneros, de los estilos, de la transposición. Buenos Aires: Eterna Cadencia Editora. 
Turnes, P. (2015). "La milonga del destino. Héroes y anti-héroes en Un tal Daneri, de Alberto Breccia y Carlos Trillo", Acta lassyensia Comparationis, 15, enero de 2015, Universidad Alexandru loan Cuza, Facultad de Letras, Dpto. de Literatura Comparada, Iasi, Rumania, pp. 189-197.

Abstract: In 1978 the volume Breccia Negro was published, which meant the presentation to an Argentine public of an Alberto Breccia consecrated as an author, awarded in Europe but relatively unknown in Argentina. In this way, it would be a re-presentation in its double sense: the renewal of the presence of the artist, who has a long career in the country; and the representation of his artistic and authorial person, in a moment where the possibility of thinking of such a figure was not only possible but it was also required by a progressively more refined, specialized, critical and demanding public. On the other hand, the same author chose to reconstruct his past as a worker in an industry from that personal and authorial perspective, making cuts and filtering what could contribute to the operation, separating it from that other that had no place in that corpus. Breccia Negro, in addition, can be read as the union of two factors that until that moment, although somehow always were present, now began to transform into deliberate action: the graphicnarrative experimentation and the political content of the comic strips.

Key words: Alberto Breccia - Dictatorship - Authorship - Cartoon.

Resumo: Em 1978, o volume Breccia Negro foi publicado, o que significou a apresenta- ção a um público argentino de um Alberto Breccia consagrado como autor, premiado na Europa, mas relativamente desconhecido na Argentina. Desta forma, seria uma re- -apresentação em seu duplo sentido: a renovação da presença do artista, que tem uma longa carreira no país; e a representação de sua pessoa artística e autoritária, em um momento em que a possibilidade de pensar em tal figura não só era possível, mas também era exigido por um público progressivamente mais refinado, especializado, crítico e exigente. Por outro lado, o mesmo autor optou por reconstruir seu passado como trabalhador em uma indústria a partir dessa perspectiva pessoal e autoral, fazendo cortes e filtragem o que poderia contribuir para a operação, separando-a da outra que não tinha lugar nesse corpus. Breccia Negro, além disso, pode ser lida como a união de dois fatores que até esse momento, embora de alguma forma sempre estiveram presentes, agora começaram a se transformar em ação deliberada: a experimentação gráfico-narrativa e o conteúdo político das tiras de quadrinhos.

Palavras chave: Alberto Breccia - Ditadura - Autoria - Desenhos animados.

[Las traducciones de los abstracts al inglés y portugués fueron supervisadas por el autor de cada artículo]

Breccia Negro: el testimonio de un autor fue publicado de la página 181 a página190 en Cuadernos del Centro de Estudios de Diseño y Comunicación Nº74 